\title{
Immobilization of high concentration hexavalent \\ chromium via core-shell structured lightweight aggregate: a promising soil remediation strategy
}

\author{
Hui Li ${ }^{\mathrm{a}, \mathrm{b},{ }^{*}}$, Yuxuan Yang ${ }^{\mathrm{a}}$, Wukui Zheng ${ }^{\mathrm{a}}$, Long Chen ${ }^{\mathrm{c}}$, Yun Bai ${ }^{\mathrm{d}}$ \\ ${ }^{a}$ College of Materials Science and Engineering, Xi'an University of Architecture and Technology, Xi'an \\ 710055, PR China \\ ${ }^{b}$ Shaanxi Ecological Cement \& Concrete Engineering Technology Research Center, Xi'an 710055, PR \\ China \\ ${ }^{c}$ Department of Civil and Environmental Engineering, Northeastern University, Boston, MA, USA \\ ${ }^{d}$ Department of Civil, Environmental and Geomatic Engineering, University College London, London \\ WC1E 6BT, UK
}

*Corresponding author:

Email: sunshine_lihui@126.com (H.L.) 


\section{Abstract}

Among industrially polluted soils, chromium contaminated sites, especially hexavalent chromium contaminated $\left(\mathrm{Cr}^{6+}\right)$ sites, are particularly difficult to manage. The $\mathrm{Cr}^{6+}$ in such soils is usually at a high concentration. Several studies show that sintering and solidification are effective ways to treat $\mathrm{Cr}^{6+}$ in soil. In this study, a coreshell lightweight aggregate (CS-LWA) was prepared using $\mathrm{Cr}^{6+}$ contaminated soil as the core and clean bulk materials as a shell to seal the $\mathrm{Cr}^{6+}$ pollutant in the core, and the shell prevents it from leaching out. A reductant, pulverized coal, was added to assist the solidification and reduce chromium toxicity. The results show that this method can effectively reduce the leaching of chromium in polluted soil with varying chromium content, and that chromium leaching can be further reduced by increasing the amount of coating material. The chromium in leachate from coated CS-LWA mixed with $8 \%$ pulverized coal was only $0.02 \mathrm{mg} / \mathrm{L}$, much lower than $1042.8 \mathrm{mg} / \mathrm{L}$ in leachate from untreated chromium-contaminated soil. Moreover, the strength, density, and water absorption characteristics of CS-LWA met the Chinese national standards, enabling its use as a lightweight aggregate for construction.

Keywords: soil remediation; solidification/stabilization; pulverized coal; $\mathrm{Cr}^{6+}$; concrete; leaching; sintering

\section{Introduction}

Chromate, as a widely used industrial material, is extensively consumed in leather processing, electroplating, military equipment, alloy manufacturing, and other industries [1,2]. Sodium dichromate is the basic form produced for such purposes, typically by the calcium roasting process. This discharges 2.5 to 3 tons of slag containing $\mathrm{Cr}^{6+}$ for every ton of sodium dichromate produced [3]. Storage of chromium 
slag will eventually cause severe soil pollution, primarily with $\mathrm{Cr}^{6+}$, at the storage site. It has been reported that in the vicinity of some chromium slag storage sites in China, the $\mathrm{Cr}^{6+}$ content in the soil has reached about $7151 \mathrm{mg} / \mathrm{kg}$ (Wu et al., 2018), which is 24 times of the limit specified in various national standards [5]. What is even worse is that the $\mathrm{Cr}^{6+}$ ions leached out from the $\mathrm{Cr}^{6+}$-contaminated soil can then easily enter the human body through food chains. As is well known, $\mathrm{Cr}^{6+}$ is a toxic pollutant with strong carcinogenic effects on the human body. $\mathrm{Cr}^{6+}$ ions in soil can easily enter the human body through the food chain, leading to genotoxicity and adverse irritation reaction to human beings. Moreover, $\mathrm{Cr}^{6+}$ in the soil transports easily in water, resulting in pollution over a wide area [6]. Therefore, even after the treatment of chromium slag, the $\mathrm{Cr}^{6+}$-contaminated soil at the storage site still needs treatment to render it innocuous.

At present, the dominant approaches used in the treatment of chromium-contaminated soil include phytoremediation, solidification/stabilization (S/S), and soil washing [7-9]. Among these, phytoremediation has been extensively employed. For example, Saravanan et al. remediated $\mathrm{Cr}^{6+}$-contaminated soil by planting Vigna mungo, achieving a reduction of the $\mathrm{Cr}^{6+}$ content from $100 \mathrm{mg} / \mathrm{kg}$ to $0.958 \mathrm{mg} / \mathrm{kg}$ [10]. However, when the $\mathrm{Cr}^{6+}$ content in the soil was more than $125 \mathrm{mg} / \mathrm{kg}$, the Vigna mungo seed germination was greatly suppressed. In another study, Richter et al. used mangrove trees to biologically extract chromium element from polluted soil by chromate. They found that the maximum Cr uptake of the plants occurred at a $\mathrm{Cr}$ load of $500 \mathrm{mg} / \mathrm{L}$ at the third month (with an uptake of up to $326.72 \mathrm{mg} / \mathrm{kg} \mathrm{Cr}$ after 3 months and $126.9 \mathrm{mg} / \mathrm{kg} \mathrm{Cr}$ after 6 months). However, at the highest $\mathrm{Cr}$ load of $1000 \mathrm{mg} / \mathrm{L}$ the uptake is much lower (191.57 mg/kg Cr after 3 months and $104.6 \mathrm{mg} / \mathrm{kg} \mathrm{Cr}$ after 6 months) [11]. On the other hand, solidification/stabilization is also a preferred method for treating Cr. For instance, 
Yuan et al. mixed the sodium sulfide with $\mathrm{Cr}^{6+}$-contaminated soil for solidification treatment, successfully reducing the $\mathrm{Cr}^{6+}$ concentration in the leachate from $663.98 \mathrm{mg} / \mathrm{L}$ to $0.84 \mathrm{mg} / \mathrm{L}$. This method can effectively reduce the leaching of $\mathrm{Cr}^{6+}$, but sodium sulfide dissolves easily in water and may thus decompose in the environment, leading to the failure of $\mathrm{Cr}$ solidification. Moreover, when sodium sulfide meets acid, it will produce hydrogen sulfide, a dangerous substance to the human body [12]. Gattullo et al. used the glass and aluminum recovered from municipal solid wastes as solidification agents to achieve more than $90 \%$ immobilization of $\mathrm{Cr}^{6+}$ in soil through the alkaline hydrothermal method. However, 3D microstructural analyses showed a limited compaction of the soil, with $20 \%$ internal porosity remained in the newly formed aggregates [13]. Zou et al. used a VFS solution containing acetic, propionic, and butyric acids in the ratio 2:4:1 to wash the chromium-contaminated soil around a smelter. They found that, although this technology has an improved efficiency for removing vanadium, it can only remove $23.55 \%$ of $\mathrm{Cr}$. Therefore, it can be concluded that there remains risks or problems in dealing with $\mathrm{Cr}$ contaminated soil by the above three methods. [14]. To be more specific, to deal with the contaminated soil with high concentrations of $\mathrm{Cr}$, the efficiency of the phytoremediation method is limited [15]. In the case of solidification, there may be a risk of secondary leaching due to the failure in the treatment by chemical solidification [16]. Finally, the effectiveness of removing Cr by washing the soil is also limited because the leaching solution itself may need treatment to render it harmless [17]. Hence, a more effective method still needs to be developed for the treatment of the contaminated soil containing high concentrations of $\mathrm{Cr}^{6+}$.

Recently, several studies have shown that polluted materials containing $\mathrm{Cr}$ can be well solidified when calcinated at temperatures above $1000^{\circ} \mathrm{C}$. For example, Chen et 
al. sintered the lead-, nickel-, and chromium-contaminated soils to produce red brick, in which more than $95 \%$ of the $\mathrm{Ni}$ and $\mathrm{Cr}$ were immobilized [18]. Zhang et al. used an argon-oxygen-decarburization (AOD) stainless steel slag as the raw material to manufacture glass ceramics. After heating at $1500^{\circ} \mathrm{C}$, less than $1.5 \mathrm{mg} / \mathrm{L} \mathrm{Cr}$ was present leached out from the ceramics. Whilst these results indicated that the treatment of $\mathrm{Cr}^{6+}$ contaminated soil by sintering can effectively reduce its impact on the environment, further study is still needed before it can be completely harmless [19].

In this paper, attempts have, therefore, been made to produce a lightweight aggregate with a core-shell structure whereby the $\mathrm{Cr}^{6+}$-contaminated soil was used to form the core while some clean materials were employed as coating to form the shell. It is anticipated that this core-shell structure can combine the advantages of calcination with the physical barrier provided by the shell to effectively reduce the leaching of $\mathrm{Cr}^{6+}$ from the core-shell lightweight aggregate (CS-LWA). In addition, pulverized coal was applied as a reductant with the aim of reducing the toxic $\mathrm{Cr}^{6+}$ to less harmful $\mathrm{Cr}^{3+}$. Using this method, not only the $\mathrm{Cr}^{6+}$ leached out from the CS LWA can be kept at a very low level, the highly $\mathrm{Cr}^{6+}$-contaminated soil could also be converted into a building material, thus contributing to the development of circular economy by transforming a hazardous waste into a useful, non-toxic resource.

\section{Experiment}

\subsection{Materials}

In order to analyze the changes of $\mathrm{Cr}$ content in soil, potassium chromate was added to the natural clean soil to simulate contaminated soil $[20,21]$. First, the collected soil (from Huyi District of Xi'an city, China) was screened to remove impurities such as gravels, plant rhizomes, and leaves, and then the soil was naturally dried and crushed. 
Next, potassium chromate was added to the above sample. After mixing, the sample was dried in a blast furnace at $110{ }^{\circ} \mathrm{C}$ for 24 hours and ground in a ball mill for 60 minutes. The ground contaminated soil was sifted by a 200 -mesh sieve. Sampling locations and appearance of the soil were shown in Fig. S1. Pulverized coal was obtained from the Shaanxi Coal and Chemical Industry Group Co. Ltd., China. Potassium chromate pellets $(99.8 \%)$ and sodium borate $(99.9 \%)$ were obtained from the Tianjin Fuchen Chemical Co. Ltd., China. Fly ash was collected from an industrial power plant situated in Henan Province, China. The chemical characteristics of the soli and fly ash are shown in Table S1. The results of proximate analysis of the pulverized coal are shown in Table S2. The mineral composition of soil is shown in Fig. 1. The cation exchange capacity of the soil is $22 \mathrm{meq} / 100 \mathrm{~g}$ and density was $6190 \mathrm{~cm}^{3} / \mathrm{g}$. The BET surface areas of the processed soil and fly ash is $2.4 \mathrm{~m}^{2} / \mathrm{g}$ and $18.7 \mathrm{~m}^{2} / \mathrm{g}$.

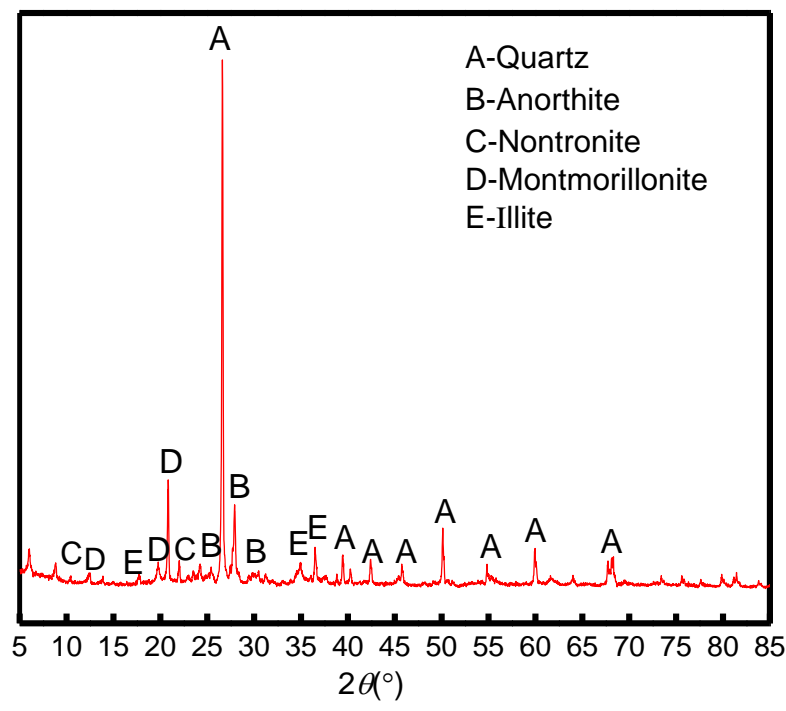

Figure 1. XRD analyses of the soil 


\subsection{Experimental methods}

\subsubsection{Preparation of coating material}

The coating material was made by mixing sodium borate, soli and fly ash in the proportions 3:60:40. This mixture was grounded for $60 \mathrm{~min}$ in a ball mill, resulting in material able to pass through a 200 -mesh sieve.

\subsubsection{Preparation of CS-LWA}

We simulated contaminated soil by adding potassium chromate to soli. After mixing, it was dried at $110^{\circ} \mathrm{C}$ in a blast roaster for $24 \mathrm{~h}$ and grounded for $60 \mathrm{~min}$ in a ball mill. The final material was able to pass through a 200 -mesh sieve.

Three samples of prepared simulated contaminated soil were mixed with different amounts of pulverized coal $(3 \%, 5 \%, 8 \%)$. These mixtures, along with contaminated soil without addition of pulverized coal as a control, were granulated using a disc granulator with deionized water as the binder. Finally, the four groups of uncoated green body samples were dried in a blower dryer at $105^{\circ} \mathrm{C}$ for $2 \mathrm{~h}$.

The samples were then loaded into another disc granulator and the prepared coating material was added to cover the green body. The adhesive used to bond the coating material was anhydrous ethanol.

The samples were then heated from an initial temperature of $25^{\circ} \mathrm{C}$ to $450^{\circ} \mathrm{C}$ at the rate of $5^{\circ} \mathrm{C} / \mathrm{min}$ in a muffle furnace and kept at $450^{\circ} \mathrm{C}$ for $30 \mathrm{~min}$, then further heated to $1130^{\circ} \mathrm{C}$ and kept at $1130^{\circ} \mathrm{C}$ for $15 \mathrm{~min}$ [22]. Finally, the samples were cooled naturally to room temperature, then stored in a desiccator ready for analysis. The experimental process is shown in Fig.2 and the appearance of the CS-LWA in Fig. 3. 


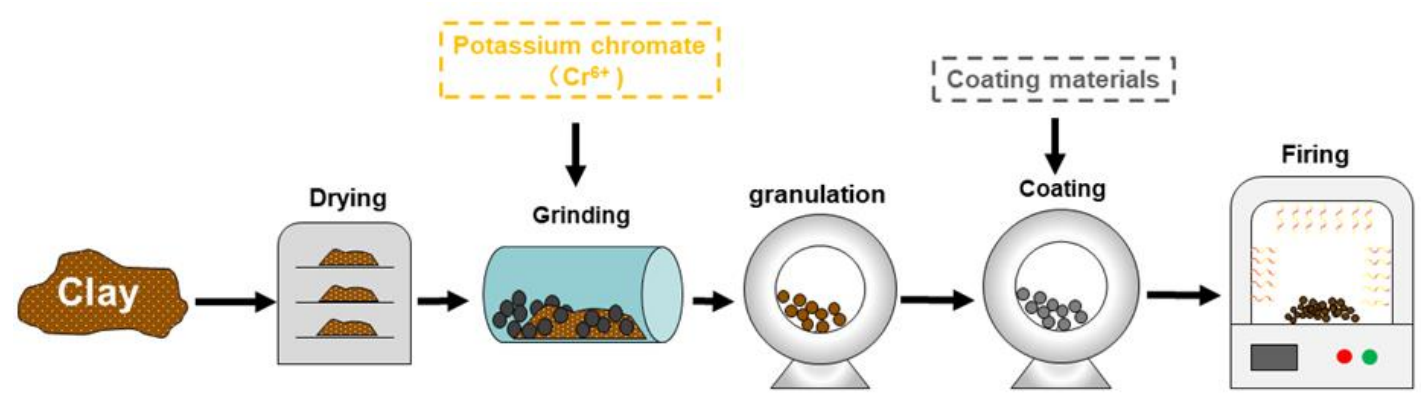

Figure 2. The experiment process of CS-LWA preparation

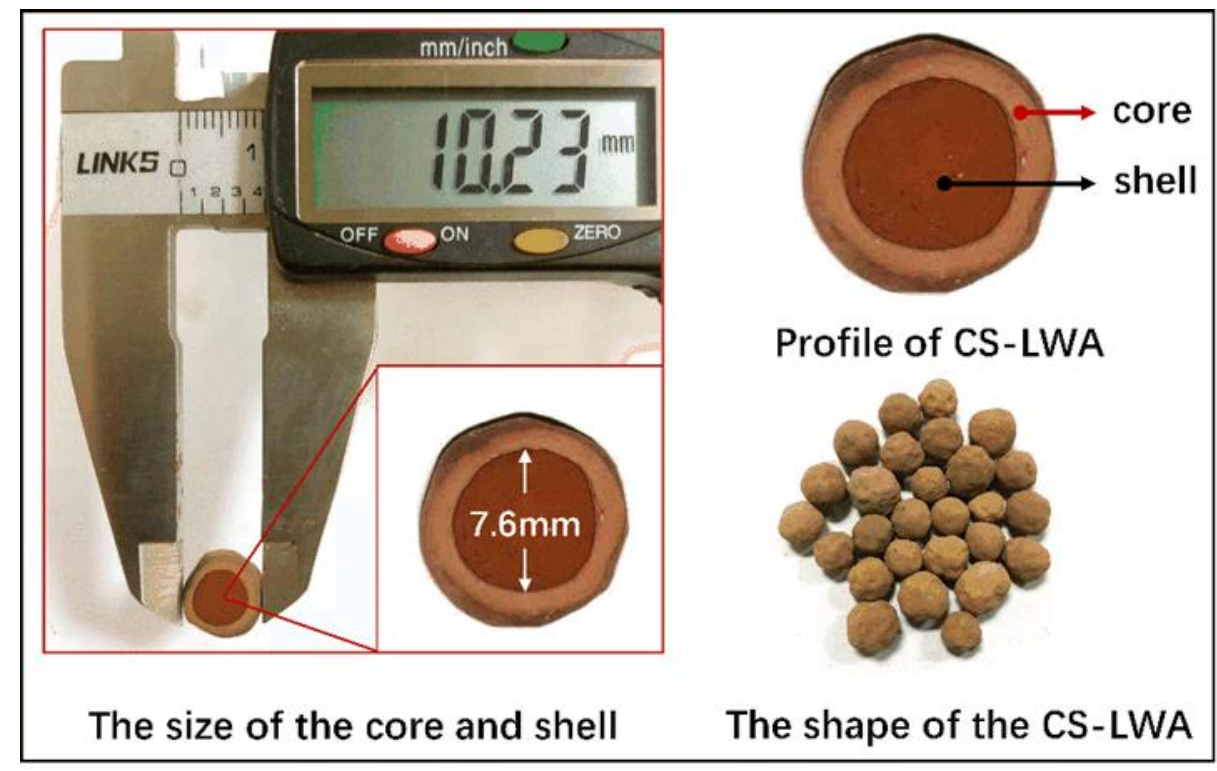

Figure 3. The appearance of the CS-LWA

\subsubsection{Preparations of uncoated LWA}

In order to compare the solidification effect and physical performance of CS-LWA and uncoated uncoated LWA containing Cr, four samples were prepared by the same granulation and firing process using the same raw materials, with and without pulverized coal $(3 \%, 5 \%, 8 \%)$. In order to ensure that the content of contaminated soil in CS-LWA was the same as that in these uncoated LWA samples, the same quantity of each type was weighed before the leaching test. 


\subsubsection{Testing methods}

The chemical composition of soils and fly ash was analyzed using a Bruker S4 Pioneer XRF spectrometer. X-ray photoelectron spectroscopy (XPS) analysis of LWA samples was carried out with an Escalab 250 Xi XPS spectrometer (Thermo-Fisher Scientific, USA).

$\mathrm{Cr}$ leaching tests were performed using a standard hazardous waste toxicity characteristic leaching procedure provided by the Ministry of Ecology and Environment of China (HJ 557-2010). Samples were mixed with pure water extractant, then vibrated for $8 \mathrm{~h}$ at 120 oscillations per minute and finally allowed to stand for $16 \mathrm{~h}$. The leachate solution was filtered and analyzed using a PerkinElmer Optima 8000 DV Inductively Coupled Plasma Optical Emission Spectrometer. The leaching tests for each type of LWA were carried out in the same volume of leaching solution.

Physical properties tests were conducted according to China National Standard GB/T 17431.2-2010, lightweight aggregate and its test method [23]. The microscopic appearance of the samples was analyzed using a FEI Verios 460 scanning electron microscope (SEM). The pore structure of the samples was analyzed using a Micromeritics Auto IV. Energy dispersive X-ray spectroscopy (EDS) analysis was performed using an FEI Quanta 200 SEM. The optical micrograph of the CS-LWA was taken using an Olympus BX61. The mineral phase of soil and fly ash was analyzed using Rigaku D-MAX/2500PCX. We used CasaXPS Software to calculate and analyze the peak area proportions for $\mathrm{Cr}^{6+}$ and $\mathrm{Cr}^{3+}$. The BET surface area of the soil and fly ash was tested by using a Micromeritics ASAP2460. The density of the soil was tested by using a Quantachrome Corporation true density analyzer. The cation exchange capacity of the soil was measuring by barium isotope method. 


\section{Results and discussion}

\subsection{Effect of core-shell structure and pulverized coal content on $\mathrm{Cr}^{6+}$ solidification}

In order to study the effect of this novel method with varying $\mathrm{Cr}^{6+}$ contents, the content of $\mathrm{Cr}^{6+}$ in the simulated soil varied from $2000-16000 \mathrm{mg} / \mathrm{kg}$, while the amount of coating material per $1000 \mathrm{~g}$ of $\mathrm{Cr}^{6+}$ contaminated soil remained constant at $300 \mathrm{~g}$. As $\mathrm{Cr}^{6+}$ content increases, the leaching concentration of $\mathrm{Cr}$ in uncoated LWA significantly increases (Fig. 4). On the contrary, in CS-LWA an increase in Cr content has a significantly smaller effect on $\mathrm{Cr}$ leaching concentration than it does in uncoated LWA.

These results show that the core-shell structure can significantly reduce $\mathrm{Cr}$ leaching under varying $\mathrm{Cr}^{6+}$ contents.

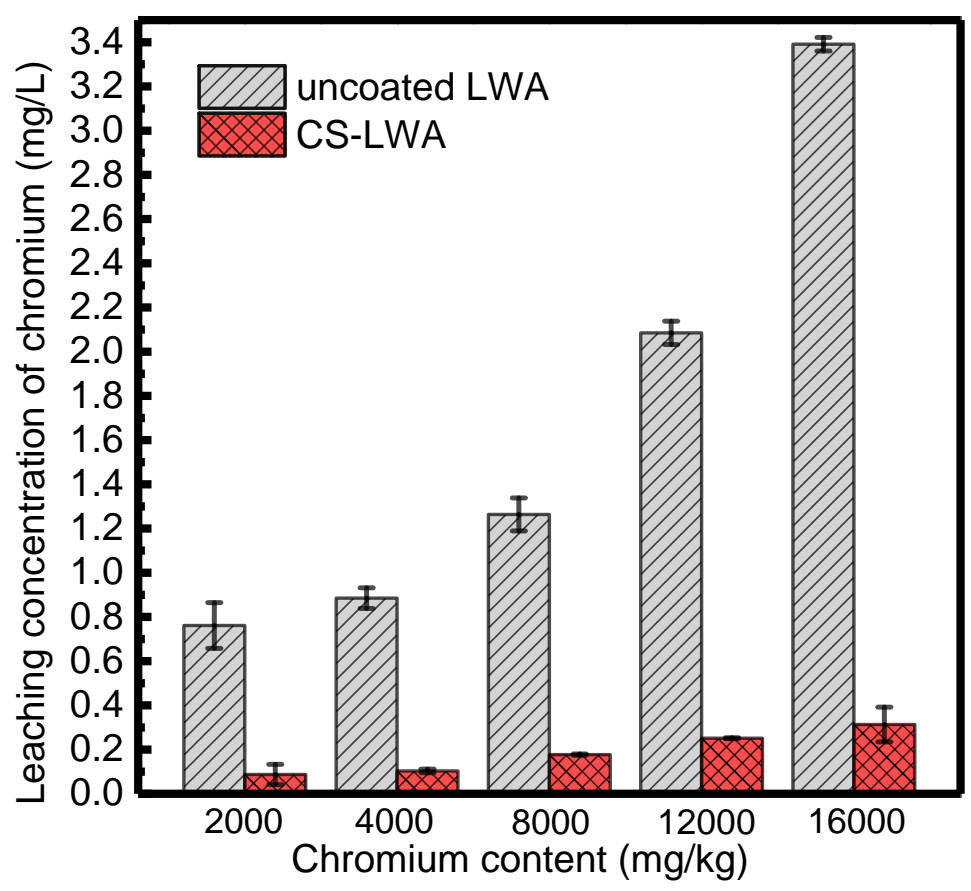

Figure 4. Effect of chromium content on the immobilization of $\mathrm{Cr} 6+$ in lightweight aggregate with (CS-LWA) and without (LWA) core-shell structure. 
In order to study the effect of the amount of coating material on the solidification effect of $\mathrm{Cr}, \mathrm{Cr}^{6+}$-contaminated soil $(12000 \mathrm{mg} / \mathrm{kg})$ was used, and the amount of coating material varied from $200-1000 \mathrm{~g} / \mathrm{kg}$. It can be found that the leaching concentration of Cr decreases gradually as the amount of coating material increases (Fig. 5). The leaching concentration of $\mathrm{Cr}$ reaches a minimum of $0.043 \mathrm{mg} / \mathrm{L}$ when the proportion of coating material is $1000 \mathrm{~g} / \mathrm{kg}$. This indicates that higher amount of coating material led to more efficient immobilization of Cr. This is likely because the thickness of the shell gradually improves with the increase of coating materials amount, which more effectively prevents the leaching of $\mathrm{Cr}$ in the core. Fig. 6 shows a cross-section of CSLWA green body with differing amounts of coating materials. It is directly observed that the thickness of the shell increases with increasing coating materials.

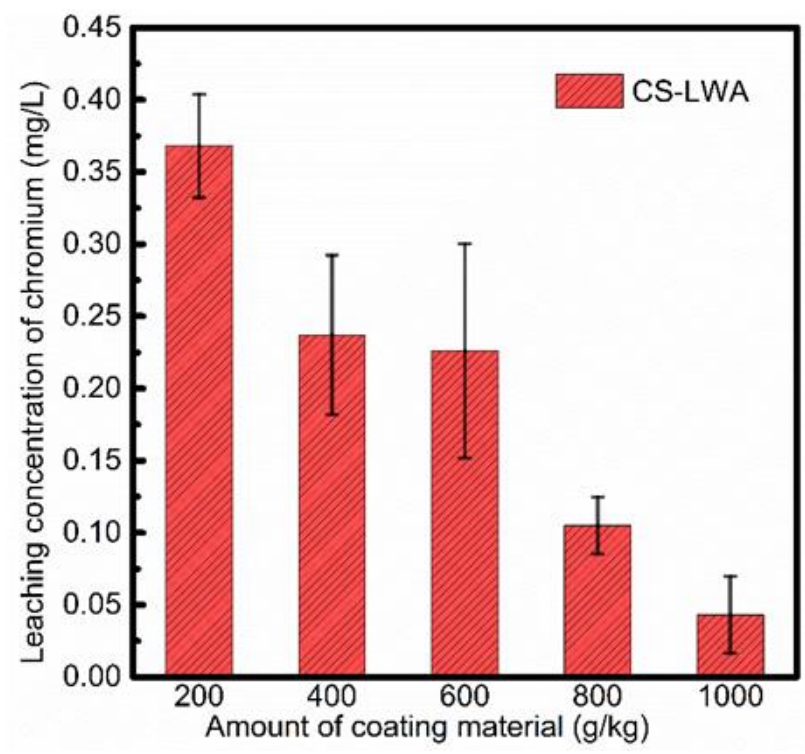

Figure 5. Effect of varying amounts of coating material on the immobilization of Cr6+ in lightweight aggregate with core-shell structure (CS-LWA). 


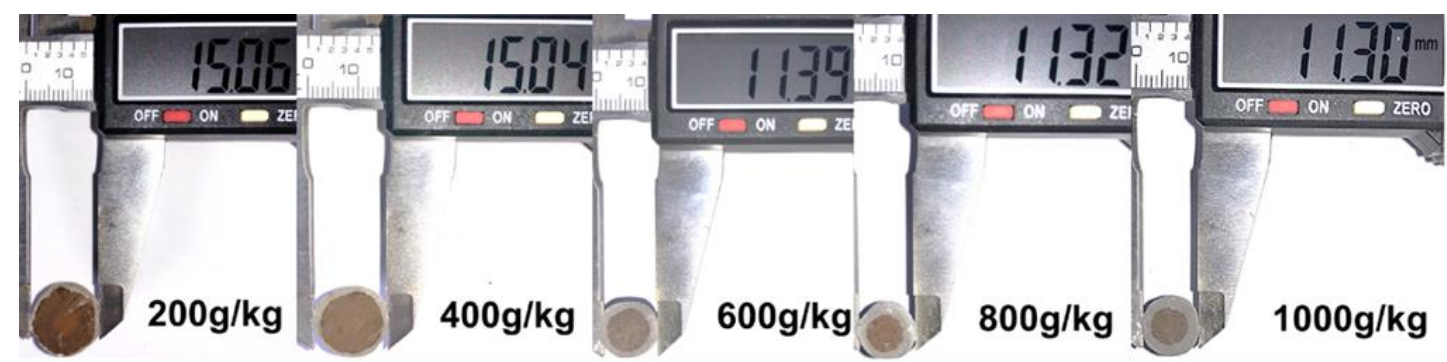

Figure 6. Cross-section of CS-LWA green body with different amounts of coating materials.

The effect of core-shell structure and pulverized coal content on solidification was studied and compared with uncoated LWA. The concentration of $\mathrm{Cr}^{6+}$ in soil was $12000 \mathrm{mg} / \mathrm{kg}$, which was selected to represent real contaminated soil [24]. The amount of coating material for $1000 \mathrm{~g} \mathrm{Cr}^{6+}$ contaminated soil was $300 \mathrm{~g}$. Fig. 7 shows that the Cr content of leachate from CS-LWA is much lower than that of uncoated LWA. The leachate Cr levels of LWA and CS-LWA without pulverized coal are $1.689 \mathrm{mg} / \mathrm{L}$ and $0.221 \mathrm{mg} / \mathrm{L}$, respectively, demonstrating that CS-LWA has a higher immobilization effect on $\mathrm{Cr}$. Furthermore, as the pulverized coal content increases, the $\mathrm{Cr}$ leached from each LWA decreases. When the pulverized coal content is $8 \%$ by weight, only 0.02 $\mathrm{mg} / \mathrm{L} \mathrm{Cr}$ leaches out. 


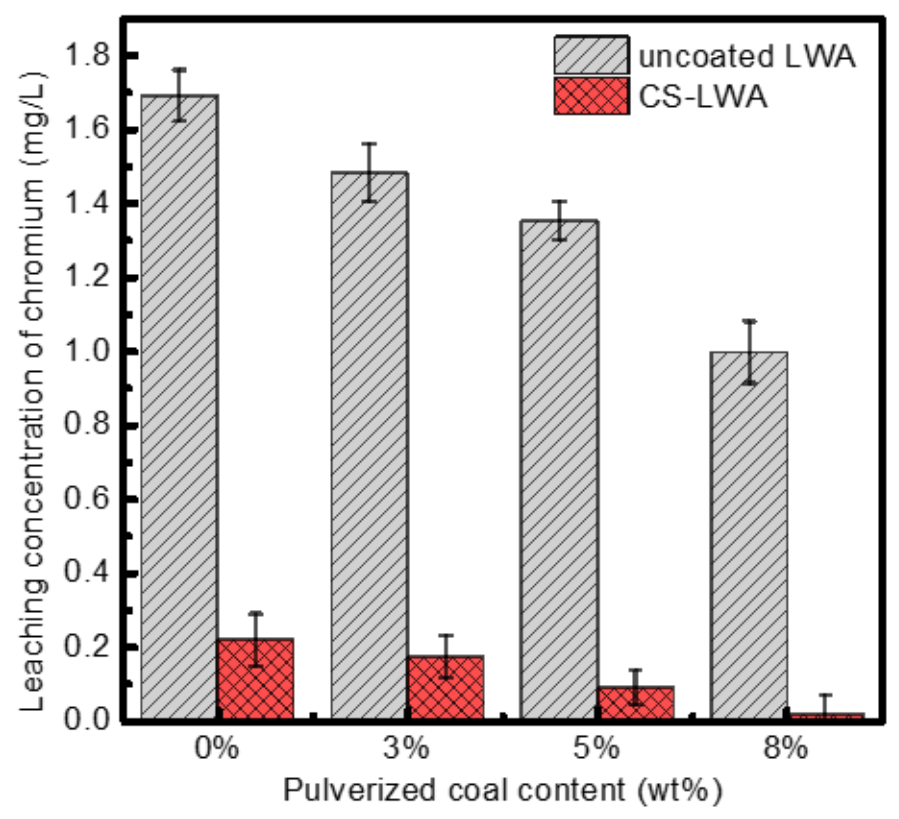

Figure 7. Effect of varying pulverized coal content on the immobilization of $\mathrm{Cr} 6+$ in lightweight aggregate with (CS-LWA) and without (LWA) core-shell structure.

Several other published chromium pollution treatment results are compared with the CS-LWA method in Table 1. It can be seen that there is a huge difference in the total chromium content and the degree of leaching between different untreated raw materials. This is because the $\mathrm{Cr}$ of different raw materials are in different existence form. $\mathrm{Cr}^{6+}$ is easier to leach out and more difficult to treat with than $\mathrm{Cr}^{3+}$. In this paper, $\mathrm{Cr}$ in contaminate soil was mixed in the form of $\mathrm{Cr}^{6+}$, therefore, it can be seen that the leaching amount is very high before treatment. A leaching test performed on $100 \mathrm{~g}(\mathrm{Cr}$ content $1200 \mathrm{mg}$ ) chromium-contaminated soil before sintering showed that 1042.8 $\mathrm{mg} / \mathrm{L} \mathrm{Cr}$ leached from it, constituting almost all the $\mathrm{Cr}$ mixed. However, after the CSLWA treatment, the leaching amount of $\mathrm{Cr}$ can be reduced to $0.02 \mathrm{mg} / \mathrm{L}$. It indicated 
that this method can effectively deal with the $\mathrm{Cr}^{6+}$. It can also be seen from Table 1 that the treatment temperature of CS-LWA method is at a low level compared with other methods, which reduce the energy consumption and cost. In summary, the above results show that the core-shell structure cooperative reductant method can effectively immobilize $\mathrm{Cr}^{6+}$, while the spherical shell can reduce $\mathrm{Cr}$ leaching and the addition of pulverized coal can enhance Cr solidification.

Table 1 Comparison of CS-LWA with other similar chromium pollution treatment methods

\begin{tabular}{lccccc}
\hline \multicolumn{1}{c}{ Materials } & $\begin{array}{c}\text { Content } \\
\text { of } \mathrm{Cr} \\
(\mathrm{mg} / \mathrm{kg})\end{array}$ & $\begin{array}{c}\text { Treatment } \\
\text { temperature } \\
\left({ }^{\circ} \mathrm{C}\right)\end{array}$ & $\begin{array}{c}\text { Cr leached } \\
\text { concentration } \\
\text { before } \\
\text { treatment(mg/L) }\end{array}$ & $\begin{array}{c}\text { Cr leached } \\
\text { concentration } \\
\text { after treatment } \\
(\mathrm{mg} / \mathrm{L})\end{array}$ & Reference \\
\hline $\begin{array}{l}\text { Cr-contaminated } \\
\text { soils }\end{array}$ & 4800 & 1000 & 106 & 2.9 & Chen et al. [18] \\
$\begin{array}{l}\mathrm{Stainless} \mathrm{steel} \\
\text { slag, } \mathrm{SiO}_{2},\end{array}$ & 11550 & 1500 & - & 0.14 & $\begin{array}{c}\text { Zhang et al. } \\
\text { [19] }\end{array}$ \\
$\begin{array}{l}\mathrm{Al} \mathrm{O}_{3} \\
\text { Sewage sludge } \\
\text { biochar } \\
\text { electroplating } \\
\text { sludge, MSWI } \\
\text { fly ash }\end{array}$ & 3475 & 1100 & 0.02 & 0.004 & Li et al. [25] \\
$\begin{array}{l}\text { Cr-contaminated } \\
\text { soils, pulverized } \\
\text { coal }\end{array}$ & 12000 & 1130 & 1042.8 & 0.02 & Yue et al. [26] \\
\hline
\end{tabular}




\subsection{Solidification mechanism of Cr by CS-LWA}

In order to explain the lower Cr leaching rate of the core-shell structure with added pulverized coal, the profile of the core-shell interface area was investigated with optical and electron microscopy. Fig. 8 shows that there are obvious differences in the morphology of shell and core. The core area is porous, while the shell area is dense. This is because there is a large amount of carbon in the pulverized coal, which will be converted to $\mathrm{CO}_{2}$ gas under high temperature, thereby leaving a large number of pores in the core. However, there are not many gas-producing components in the spherical shell materials during the heating process, and as a result the components of the spherical shell materials will instead melt to produce dense fired products. The above differences might explain the different morphologies of the core and shell. Thus, after sintering, a dense protective layer is formed on the surface of CS-LWA granules, which can seal Cr pollutant in the core and prevent it from leaching out.

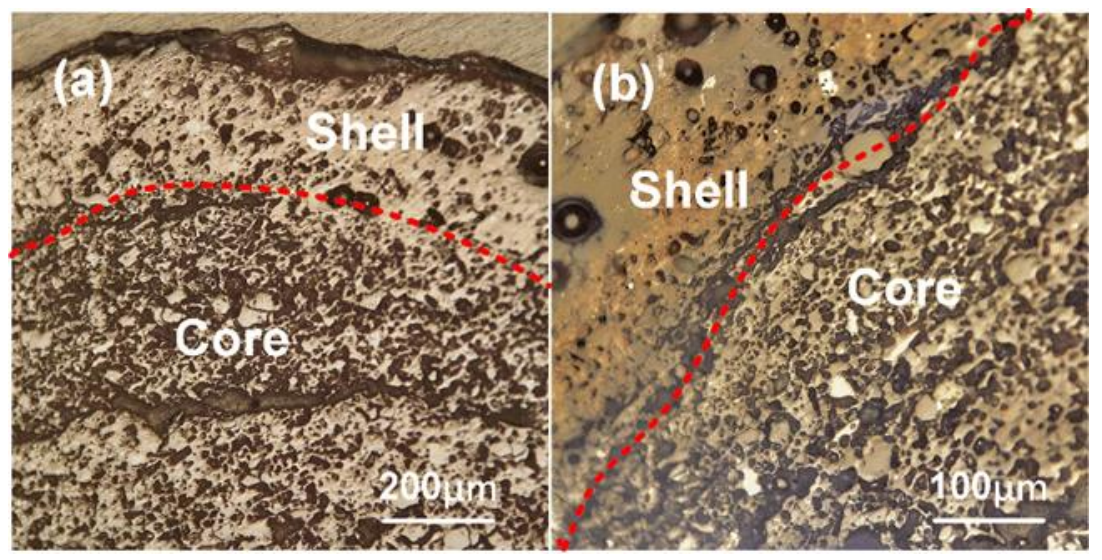

Figure 8. Optical micrograph of core-shell interface section of CS-LWA containing 8\% (wt) pulverized coal: (a) 50x magnification; (b)100x magnification. 
In order to further confirm this observation, the distribution of chromium in the coreshell interface before and after leaching was analyzed by EDS mapping. It can be seen from Fig. $9 \mathrm{~b}$ that before leaching, $\mathrm{Cr}$ is mainly distributed in the core area, and there is almost no Cr in the shell. At the same time, as seen in Fig. 9c and 6d, the main elements $\mathrm{Al}$ and $\mathrm{Si}$ in the shell and the core are uniformly distributed. After leaching, as shown in Fig. 9e-h, Cr is still mainly distributed in the core area, with only a small amount of $\mathrm{Cr}$ detected in the shell area. Si and $\mathrm{Al}$ are still evenly distributed. The results shows that $\mathrm{Cr}$ is present primarily in the core area both before and after leaching, and there is no large-scale outward diffusion. This indicates that the dense shell can indeed seal $\mathrm{Cr}$ pollutant in the core and prevent the leaching of $\mathrm{Cr}$.

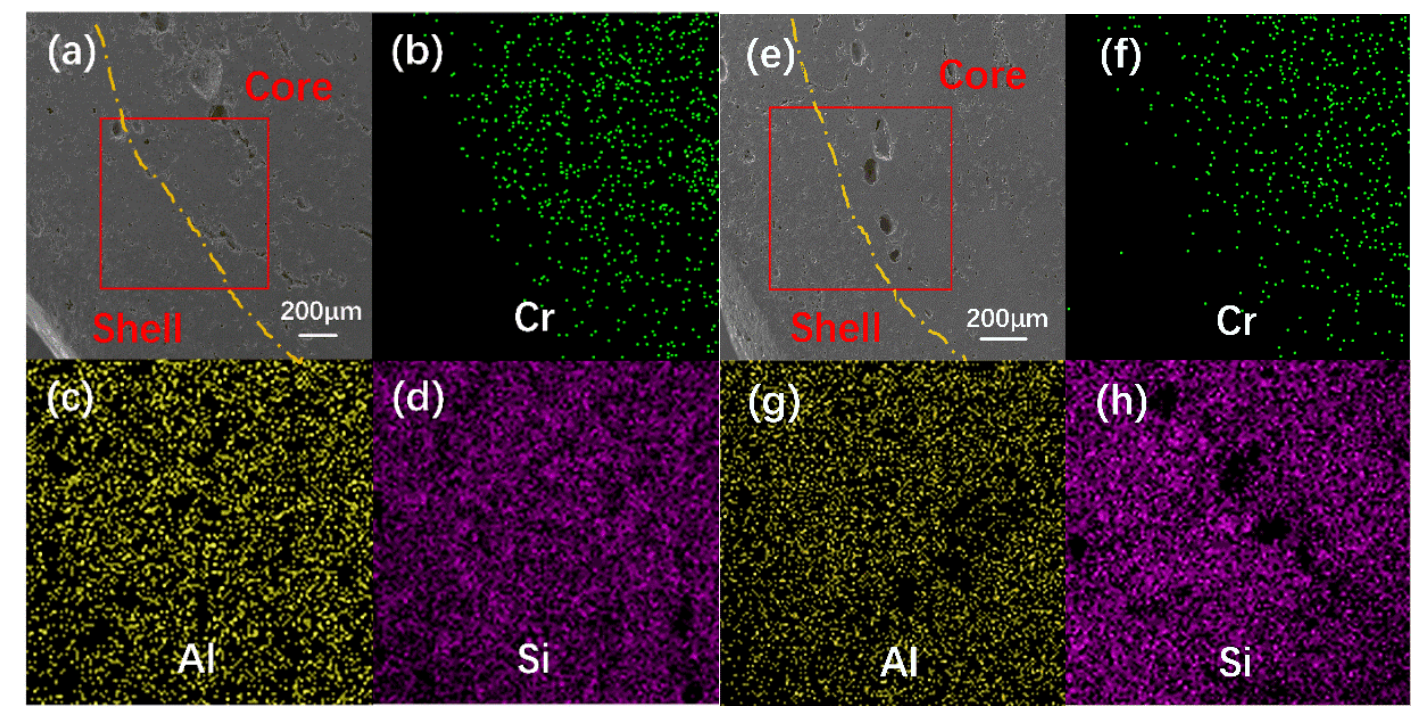

Figure 9. EDS mapping of core-shell interface section of CS-LWA containing no pulverized coal, before (a-d) and after (e-h) leaching. (a, e) Profile morphology and selection area of mapping; the lower left corner of the picture is near the edge of the shell area, the upper right corner is the core area, and the yellow frame denotes the EDS mapping scanning area; (b, f) distribution of $\mathrm{Cr}$; (c, g) distribution of $\mathrm{Al}$; $(\mathrm{d}, \mathrm{h})$ distribution of Si. 


\subsection{Effect of pulverized coal on the content of $\mathrm{Cr}^{3+}$ and $\mathrm{Cr}^{6+}$ in $\mathrm{LWA}$}

In order to explain the lower level of Cr leaching caused by the addition of pulverized coal, LWA granules containing different amounts of $\mathrm{Cr}$ were analyzed by XPS. As shown in Fig. 10, the peaks of $579.4 \mathrm{eV}$ (blue) are attributed to the $\mathrm{Cr} 2 \mathrm{p}$ of $\mathrm{Cr}^{6+}$, while the peaks at $586.8 \mathrm{eV}$ and $577 \mathrm{ev}$ occurred in response to the $\mathrm{Cr} 2 \mathrm{p}$ of $\mathrm{Cr}^{3+}[27,28]$. As the content of pulverized coal increases, the peak intensity of $\mathrm{Cr}^{6+}$ is weakened, while the $\mathrm{Cr}^{3+}$ peaks are enhanced.

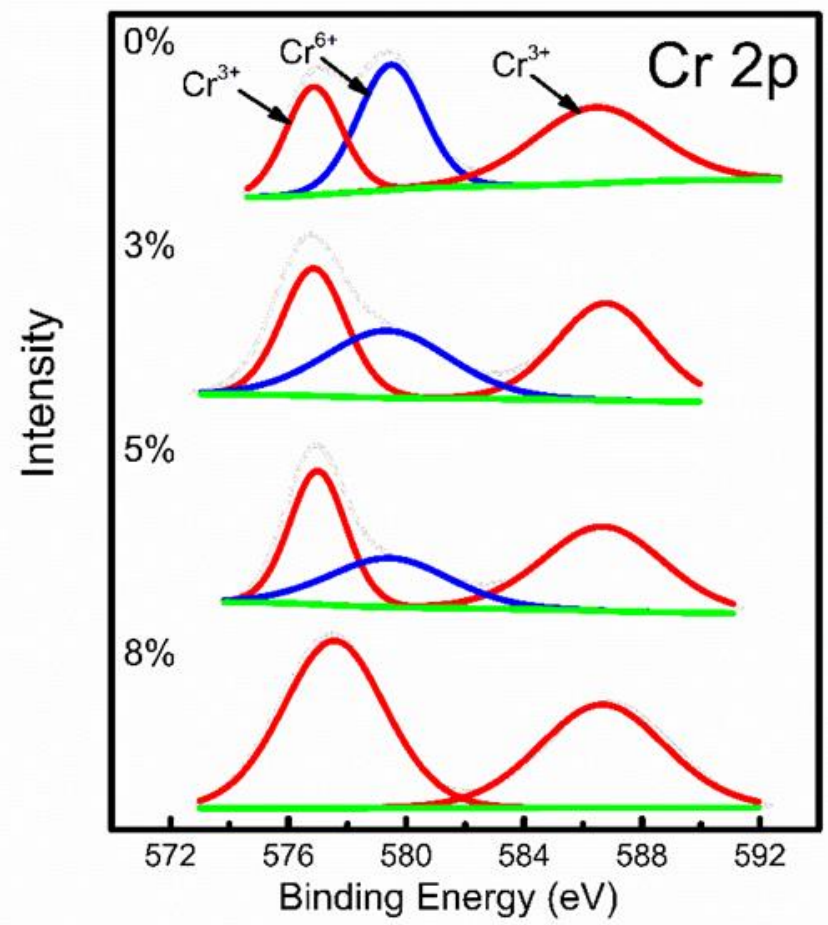

Figure 10. XPS analysis of $\mathrm{Cr} 2 \mathrm{p}$ at different pulverized coal content levels

The peak area proportions for $\mathrm{Cr}^{6+}$ and $\mathrm{Cr}^{3+}$ was shown in Table 2. As the pulverized coal content increases from $0 \%$ to $8 \%$, the proportional area under the $\mathrm{Cr}^{6+}$ curve decreased from $41.07 \%$ to $0 \%$, and the proportional area under the $\mathrm{Cr}^{3+}$ curve increased 
from $58.93 \%$ to $100 \%$. At a pulverized coal content of $8 \%$, the $\mathrm{Cr}^{6+}$ peak disappeared completely. Changes in XPS peak intensity can indicate changes in the elemental content in the sample $[29,30]$.

Table 2. $\mathrm{Cr}^{3+}$ and $\mathrm{Cr}^{6+}$ peak splitting for core material

\begin{tabular}{lccccc}
\hline & & \multicolumn{4}{c}{ Pulverized coal content (\% wt) } \\
\cline { 3 - 6 } & & 0 & 3 & 5 & 8 \\
\hline \multirow{2}{*}{ Area under peak(s) (\%) } & $\mathrm{Cr}^{3+}$ & 58.93 & 67.88 & 74.97 & 100 \\
& $\mathrm{Cr}^{6+}$ & 41.07 & 32.12 & 25.03 & - \\
\hline
\end{tabular}

The results of the XPS analysis show that $\mathrm{Cr}^{6+}$ in LWA appears to be converted into $\mathrm{Cr}^{3+}$ proportionately with increasing pulverized coal content. This is mainly because, during the high-temperature sintering process, $\mathrm{C}$ in the pulverized coal under high temperature will reduce $\mathrm{Cr}^{6+}$ to $\mathrm{Cr}^{3+}$ in the spherical core [31].A large number of studies have shown that $\mathrm{Cr}^{3+}$ is relatively difficult to leach in aqueous phase compared to $\mathrm{Cr}^{6+}$ [32-34]. Fan et al. proposed that $\mathrm{Cr}^{6+}$ usually exists as the highly soluble and toxic oxyanion such as $\mathrm{CrO}_{4}{ }^{2-}$, and $\mathrm{Cr}^{3+}$ is mostly immobile as $\mathrm{Cr}_{2} \mathrm{O}_{3}$ solid and less toxic [35]. Therefore, we believe that with the increase of the amount of pulverized coal, more $\mathrm{Cr}^{6+}$ is converted into $\mathrm{Cr}^{3+}$, reducing the $\mathrm{Cr}$ leaching amount of LWAs.

\subsection{Effect of pulverized coal content on the performance of CS-LWA}

The compressive strength, bulk density and $1 \mathrm{~h}$ water absorption of LWA are key performance characteristics in relation to its use as a building material. The effect of pulverized coal content on those characteristics of CS-LWA and LWA was tested, as shown in Fig. 11. 


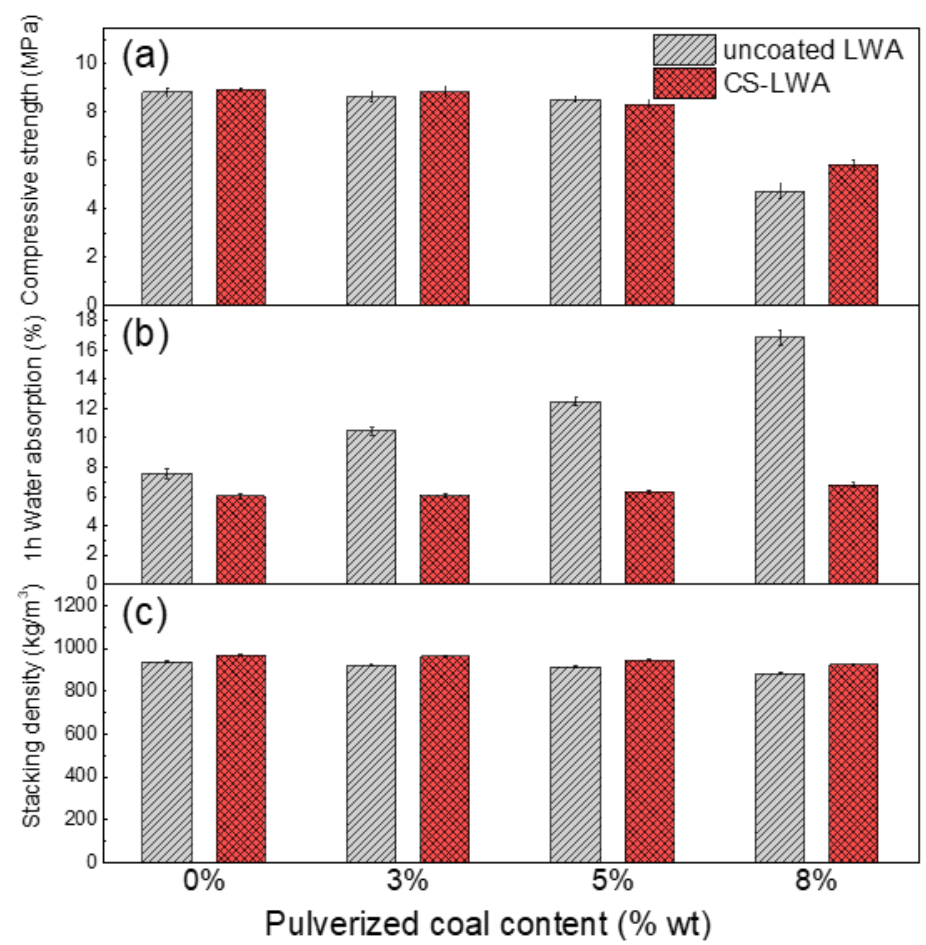

Figure 11. Effect of pulverized coal content on the performance of CS-LWA and LWA: (a) compressive strength, tested with a loading speed of $0.8-1 \mathrm{kN} / \mathrm{s}$; (b) bulk density, tested with a particle size of 5-20 mm and sample volume of $5 \mathrm{~L}$; (c) $1 \mathrm{~h}$ water absorption, cooled $500 \mathrm{~g}$ samples tested at $25^{\circ} \mathrm{C}$ after drying at $105^{\circ} \mathrm{C}$ for $2 \mathrm{~h}$.

It can be seen in Fig. 11a that the compressive strength of CS-LWA is similar to that of uncoated LWA. The addition of pulverized coal lowered the strength of both types. This became significant at $8 \%$ pulverized coal content, when the compressive strength of uncoated LWA was $8.8 \mathrm{MPa}$ compared to $4.7 \mathrm{MPa}$, and that of CS-LWA is8.9 $\mathrm{MPa}$ compared to $5.8 \mathrm{MPa}$, in each case without and with coal, respectively.

Fig. 11b shows that LWA water absorption increases with increasing pulverized coal content, from $7.51 \%$ in the absence of coal to $16.8 \%$, with an over 2 -fold increase, at $8 \%$ coal content. The water absorption of CS-LWA is about $6 \%$ regardless of coal content. 
The bulk density of both LWAs is lower with higher pulverized coal content (Fig. 11c). The bulk density of common LWA was $936 \mathrm{~kg} / \mathrm{m}^{3}$ without pulverized coal, compared to $759 \mathrm{~kg} / \mathrm{m}^{3}$ with coal, and the bulk density of CS-LWA without coal was $966 \mathrm{~kg} / \mathrm{m}^{3}$ compared to $878 \mathrm{~kg} / \mathrm{m}^{3}$ with coal. These differences are closely related to the influence of the pulverized coal on LWA microstructure. SEM and mercury injection methods were therefore used to analyze these differences in LWA microstructure.

As shown in Fig. 12, higher pulverized coal content results in larger pores and looser structure in the LWA. At 3\% pulverized coal we observe pores $0.5-1 \mu \mathrm{m}$ in diameter; at $5 \%$, the pores are more than $2 \mu \mathrm{m}$ in diameter. At $8 \%$ pulverized coal, the number of pores at both $0.5-1 \mu \mathrm{m}$ and $>2 \mu \mathrm{m}$ increased significantly.

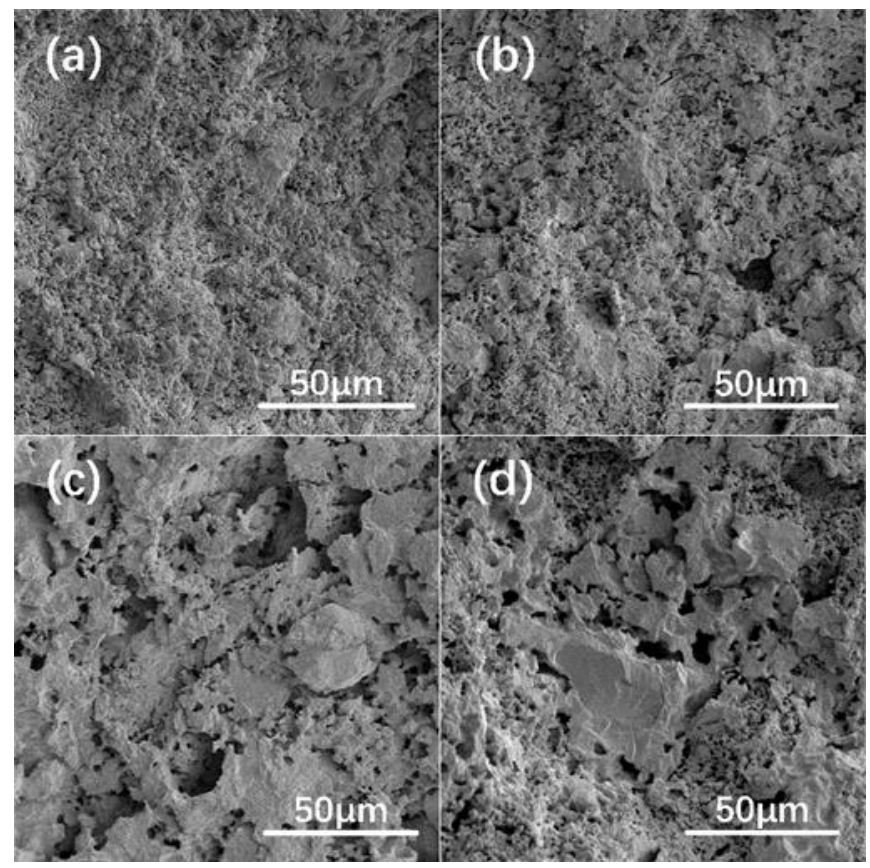

Figure 12. Scanning electron micrographs of LWA core structure at different pulverized coal content levels: (a) $0 \% \mathrm{wt}$; (b) $3 \% \mathrm{wt}$; (c) 5\% wt; (d) $8 \%$ wt.

The same phenomenon emerged during mercury injection testing. As shown in Fig. 
13, the pores in LWA are mainly distributed between $0.1 \mu \mathrm{m}$ and $10 \mu \mathrm{m}$, and the distribution peak shifts to the right with increasing pulverized coal content. The total porosity is $11.55 \%$ in the absence of coal, compared to $29.22 \%$ at $8 \%$ coal content (Table 3).

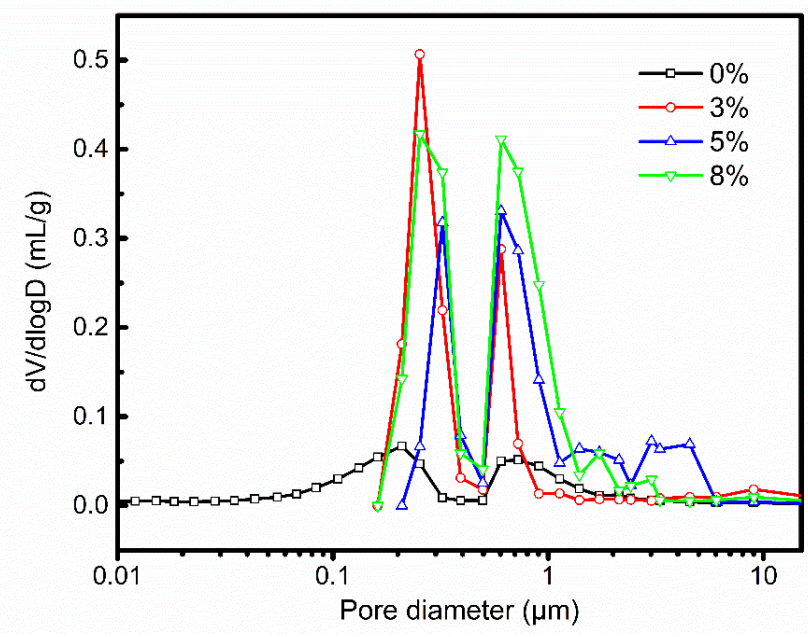

Figure 13. Pore size distribution for uncoated LWA with varying pulverized coal content

Table 3. Differences in total porosity and intrusion volume with varying pulverized coal content

\begin{tabular}{ccccc}
\hline & \multicolumn{4}{c}{ Pulverized coal content $(\% \mathrm{wt})$} \\
\cline { 2 - 5 } & 0 & 3 & 5 & 8 \\
\hline Total porosity $(\%)$ & 11.55 & 20.20 & 23.11 & 29.22 \\
Total intrusion volume (mL/g) & 0.05 & 0.14 & 0.16 & 0.22 \\
\hline
\end{tabular}

These results demonstrate that the addition of pulverized coal to LWA produced greater porosity and pore size. Such changes in pore structure are normally considered to account for the higher water absorption, lower strength, and lower bulk density of LWA. However, the water absorption of CS-LWA changes little, regardless of coal 
content. Fig. 14 shows that a layer of dense enamel product is formed on the surface of the sintered CS-LWA spherical shell, and this dense spherical shell is able to reduce the infiltration of water, thus reducing the water absorption.

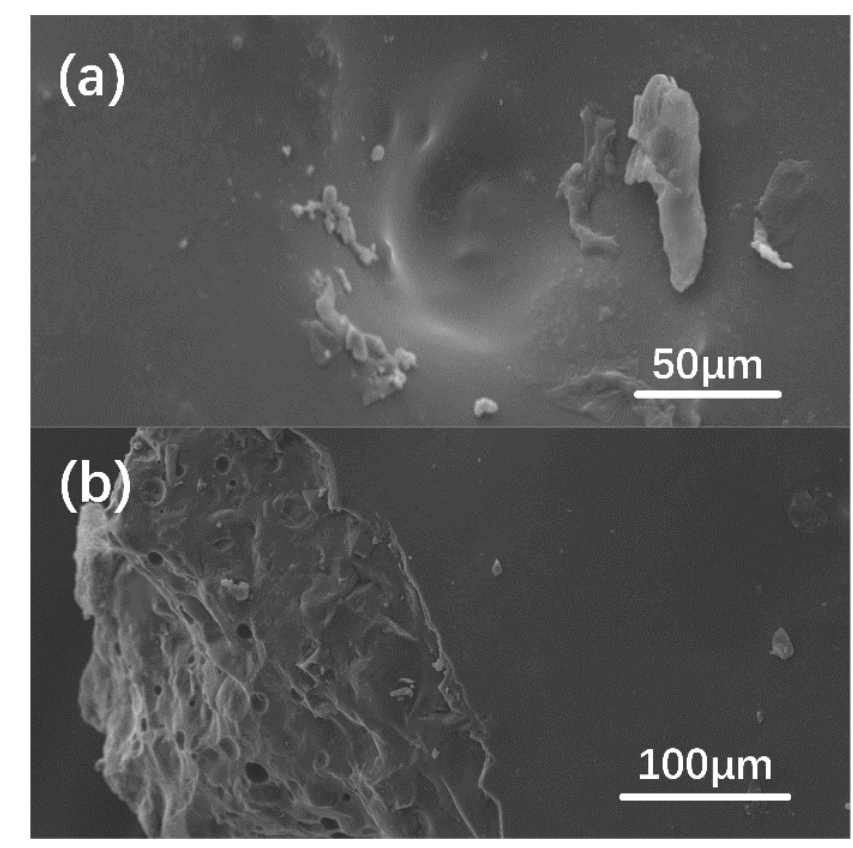

Figure 14. Scanning electron micrograph of spherical shell surface: (a) shell surface; (b) shell section.

Our results demonstrate that the stacking density, $1 \mathrm{~h}$ water absorption, and compressive strength of CS-LWA with the tested pulverized coal content levels meet the requirements of China National Standard GB/T 17431.2-2010 and can therefore be used as lightweight aggregate for concrete.

In China, the market price of lightweight aggregate of the same quality is about $\$ 120 / t$, and the CS-LWA product process can be readily scaled up for mass production. It is well suited to meet the high demand for building aggregates in China and could help to fill the current supply gap. Based on current Chinese policy, there will be financial subsidies for the treatment of heavy metal contaminated soil; as a raw material, 
Cr contaminated soil has almost no cost. Overall, the production cost of CS-LWA can be kept low, making it a good market prospect.

\section{Conclusions}

In this study, pulverized coal was added into $\mathrm{Cr}^{6+}$-contaminated soil as a reducing agent and this core mixture was granulated, then coated with a mixture of soil, fly ash and borate. Coated granules were sintered at $1130^{\circ} \mathrm{C}$ to form a core-shell structure lightweight aggregate (CS-LWA). This method effectively immobilizes and seals the chromium pollutant by solidification. The dense shell seals Cr pollutant in the core and prevents its leaching. Pulverized coal functioned to reduce $\mathrm{Cr}^{6+}$ to $\mathrm{Cr}^{3+}$, further decreasing chromium leaching. Untreated chromium-contaminated soil leached $\mathrm{Cr}$ at $1042.8 \mathrm{mg} / \mathrm{L}$, whereas leachate from CS-LWA mixed with $8 \%$ pulverized coal contained only $0.02 \mathrm{mg} / \mathrm{L}$. CS-LWA also had a stacking density of $878 \mathrm{~kg} / \mathrm{m}^{3}$, a cylinder compressive strength of $5.8 \mathrm{MPa}$, and a $1 \mathrm{~h}$ water absorption rate of $6.75 \%$, consistent with its use as a light aggregate for concrete. Compared to existing methods, which only employ the mixing and sintering of raw materials, the core shell method is less affected by the composition of the raw materials and it has wide adaptability to different types of Cr-polluted materials. However, future research on the applicability and stability of the CS-LWA process is needed to verify its potential.

\section{Acknowledgments}

Funding: This work was supported by the National Key Research and Development Program of Ministry of Science and Technology of the People's Republic of China [under Contract 2017YFC0703202-2]; the Natural Science Foundation of Shaanxi [under Contract 2019JM-117]. 


\section{References}

[1] B. Dhal, H.N. Thatoi, N.N. Das, B.D. Pandey, Chemical and microbial remediation of hexavalent chromium from contaminated soil and mining/metallurgical solid waste: a review, J. Hazard. Mater. 250 (2013) 272291.

[2] A. Shanker, B. Venkateswarlu, Chromium: environmental pollution, health effects and mode of action, in J. Nriagu (Ed.), Encyclopedia of Enviromental Health, Elsevier, London, 2011, pp. 650-659.

[3] H.M. Long, Q.M. Meng, P. Wang, T.J. Chun, Y.L. Yao, Preparation of chromiumiron metal powder from chromium slag by reduction roasting and magnetic separation, J. Iron. Steel. Res. Int. 22 (2015) 771-776.

[4] W. Wu, P. Wu, F. Yang, D.L. Sun, D.X. Zhang, Y.K. Zhou, Assessment of heavy metal pollution and human health risks in urban soils around an electronics manufacturing facility, Sci. Total Environ. 630 (2018) 53-61.

[5] Y. Teng, J. Wu, S. Lu, Y. Wang, X. Jiao, L. Song, Soil and soil environmental quality monitoring in China: a review, Environ. Int. 69 (2014) 177-199.

[6] B. Eyvazi, A. Jamshidi-Zanjani, A.K. Darban, Immobilization of hexavalent chromium in contaminated soil using nano-magnetic $\mathrm{MnFe}_{2} \mathrm{O}_{4}$, J. Hazard. Mater. 365 (2019) 813-819. 
[7] S. Ashraf, Q. Ali, Z.A. Zahir, S. Ashraf, H.N. Asghar, Phytoremediation: Environmentally sustainable way for reclamation of heavy metal polluted soils, Ecotox. Environ. Safe. 174 (2019) 714-727.

[8] G. Dermont, M. Bergeron, G. Mercier, M. Richer-Laflèche, Soil washing for metal removal: a review of physical/chemical technologies and field applications, J. Hazard. Mater. 152 (2008) 1-31.

[9] S.A.A. Tajudin, M.A.M. Azmi, A.T.A. Nabila, Stabilization/solidification remediation method for contaminated soil: a review, IOP Conf. Ser. Mater. Sci. Eng. 136 (2016) 012043.

[10] A. Saravanan, R. Jayasree, R.V. Hemavathy, S. Jeevanantham, S. Hamsini, P. Senthil Kumar, P.R Yaashikaa, V. Manivasagan, D. Yuvaraj, Phytoremediation of $\mathrm{Cr}(\mathrm{VI})$ ion contaminated soil using Black gram (Vigna mungo): assessment of removal capacity, J. Environ. Chem. Eng. 7 (2019) 103052.

[11] O. Richter, H.A. Nguyen, K.L. Nguyen, V.P. Nguyen, H. Biester, P. Schmidt, Phytoremediation by mangrove trees: experimental studies and model development, Chem. Eng. J. 294 (2016) 389-399.

[12] W. Yuan, W. Xu, Z. Wu, Z. Zhang, L. Wang, J. Bai, X. Wang, Q. Zhang, X. Zhu, C. Zhang, J. Wang, Mechanochemical treatment of $\mathrm{Cr}(\mathrm{VI})$ contaminated soil using a sodium sulfide coupled solidification/stabilization process, Chemosphere $212(2018) 540-547$. 
[13] C.E. Gattullo, C. D’Alessandro, I. Allegretta, C. Porfido, M. Spagnuolo, R. Terzano, Alkaline hydrothermal stabilization of $\mathrm{Cr}(\mathrm{VI})$ in soil using glass and aluminum from recycled municipal solid wastes, J. Hazard. Mater. 344 (2018) 381-389.

[14] Q. Zou, H. Xiang, J. Jiang, D. Li, A. Aihemaiti, F. Yan, N. Liu, Vanadium and chromium-contaminated soil remediation using VFAs derived from food waste as soil washing agents: a case study, J. Environ. Manage. 232 (2019) 895-901.

[15] C.K. Odoh, N. Zabbey, C. Sam, C.N. Eze, Status, progress and challenges of phytoremediation - an African scenario, J. Environ. Manage. 237 (2019) 365-378.

[16] Q.Y. Chen, M. Tyrer, C.D. Hills, X.M. Yang, P. Carey, Immobilisation of heavy metal in cement-based solidification/stabilisation: a review, J. Waste. Manag. 29 (2009) 390-403.

[17] W. Feng, S. Zhang, Q. Zhong, G. Wang, X. Pan, X. Xu, W. Zhou, T. Li, L. Luo, Y. Zhang, Soil washing remediation of heavy metal from contaminated soil with EDTMP and PAA: properties, optimization, and risk assessment, J. Hazard. Mater. 381 (2020) 120997.

[18] S.W. Chen, P.C. Cheng, Y.T. Tu, C.C. Chen, S.F. Cheng, Variance in heavy metal leachability of $\mathrm{Pb}-, \mathrm{Ni}-$, and $\mathrm{Cr}$-contaminated soils through red brick sintering procedure, Environ. Monit. Assess. 191 (2019) 253. 
[19] S. Zhang, Y. Zhang, Z. Qu, Physicochemical property and chromium leaching behavior in different environments of glass ceramics prepared from AOD stainless steel slag, J. Alloys Compd. 805 (2019) 1106-1116.

[20] H. Wang, H.H. Zhang, X.F. Zhang, Q. Li, C.K. Cheng, H. Shen, Z.Z. Zhang, Bioelectrochemical remediation of $\mathrm{Cr}(\mathrm{VI}) / \mathrm{Cd}(\mathrm{II})$-contaminated soil in bipolar membrane microbial fuel cells, Environ. Res. 186 (2020) 109582.

[21] J. Zhang, G. Zhang, D.Q. Cai, Z.Y. Wu, Immediate remediation of heavy metal (Cr(VI)) contaminated soil by high energy electron beam irradiation, J. Hazard. Mater. 285 (2015) 208-211.

[22] Y.X. Yang, H. Li, W.K. Zheng, Y. Bai, Z.M. Liu, J.J. Zhang, Experimental study on calcining process of secondary coated ceramsite solidified chromium contaminated soil, Sci. Adv. Mater. 11 (2019) 208-214.

[23] Standardization administration, Lightweight aggregate and its test method, http://std.samr.gov.cn/search/std?q=\%20GB\%2FT\%2017431.2-2010, 2010 (accessed 20 May 2020).

[24] B. Liu, G. Su, Y. Yang, Y. Yao, Y. Huang, L. Hu, H. Zhong, Z. He, Vertical distribution of microbial communities in chromium-contaminated soil and isolation of Cr(VI)-reducing strains, Ecotox. Environ. Safe. 180 (2019) 242-251.

[25] J. Li, G. Yu, S. Xie, L. Pan, C. Li, F. You, Y. Wang, Immobilization of heavy metals in ceramsite produced from sewage sludge biochar, Sci. Total Environ. 628-629 (2018) 131-140. 
[26] Y. Yang, J. Zhang, F. Sun, S. Wu, Y. Pan, J. Zhou, G. Qian, Heavy metal leaching and distribution in glass products from the co-melting treatment of electroplating sludge and MSWI fly ash, J. Environ. Manage. 232 (2019) 226-235.

[27] M.C. Biesinger, B.P. Payne, A.P. Grosvenor, L.W.M. Lau, A.R. Gerson, R.St.C. Smart, Resolving surface chemical states in XPS analysis of first row transition metals, oxides and hydroxides: Cr, Mn, Fe, Co and Ni, Appl. Surf. Sci. 257 (2011) 2717-2730.

[28] S. Boursiquot, M. Mullet, J.J. Ehrhardt, XPS study of the reaction of chromium (VI) with mackinawite (FeS), Surf. Interface Anal. 34 (2002) 293-297.

[29] S. Wang, L. Li, Z. Zhu, M. Zhao, L. Zhang, N. Zhang, Q. Wu, X. Wang, G. Li, Remarkable improvement in photocatalytic performance for tannery wastewater processing via $\mathrm{SnS}_{2}$ modified with $\mathrm{N}$-doped carbon quantum dots: synthesis, characterization, and 4-nitrophenol-aided Cr (VI) photoreduction, Small 15 (2019) 1804515.

[30] H. Tang, J. Wang, H. Yin, H. Zhao, D. Wang, Z. Tang, Growth of polypyrrole ultrathin films on $\mathrm{MoS}_{2}$ monolayers as high-performance supercapacitor electrodes, Adv. Mater. 27 (2015) 1117-1123.

[31] T.T. Zhao, W.Z. Ge, Y.X. Nie, Y.X. Wang, F.G. Zeng, Y. Qiao, Highly efficient detoxification of $\mathrm{Cr}$ (VI) by brown coal and kerogen: Process and structure studies, Fuel. Process. Technol. 150 (2016) 71-77 
[32] P. Zhao, H. Zhang, J. Yu, H. Gao, Y. Cao, Y. Zhu, H. Zhao, Conditions for mutual conversion of $\mathrm{Cr}(\mathrm{III})$ and $\mathrm{Cr}(\mathrm{VI})$ in aluminum chromium slag, J. Alloys Compd. 788 (2019) 506-513.

[33] S. Zhao, Z. Chen, B. Wang, J. Shen, J. Zhang, D. Li, Cr(VI) removal using different reducing agents combined with fly ash leachate: a comparative study of their efficiency and potential mechanisms, Chemosphere 213 (2018) 172-181.

[34] X. Wang, W. Liu, H. Fu, X-H. Yi, P. Wang, C. Zhao, C-C. Wang, W. Zheng, Simultaneous $\mathrm{Cr}(\mathrm{VI})$ reduction and $\mathrm{Cr}(\mathrm{III})$ removal of bifunctional MOF/titanate nanotube composites, Environ. Pollut. 249 (2019) 502-511.

[35] X.F. Fan, S.M. Ding, M.S. Chen, S.S. Gao, Z. Fu, M.D. Gong, D.C.W. Tsang Y. Wang, C.S. Zhang, Peak Chromium Pollution in Summer and Winter Caused by High Mobility of Chromium in Sediment of a Eutrophic Lake: In Situ Evidence from High Spatiotemporal Sampling, Environ. Sci. Technol. 53 (2019) 47554764. 